\title{
Study of high In-content AlInN deposition on p-Si (111) by RF-sputtering
}

\author{
Arántzazu Núñez-Cascajero ${ }^{*}$, Laura Monteagudo-Lerma ${ }^{1}$, \\ Sirona Valdueza-Felip ${ }^{1,2,3}$, Cristina Navío ${ }^{4}$, Eva Monroy ${ }^{2,3}$, \\ Miguel González-Herráez ${ }^{1}$, and Fernando B. Naranjo ${ }^{1}$ \\ ${ }^{1}$ GRIFO, Departamento Electrónica, Universidad de Alcalá, 28871 Alcalá de Henares, \\ Madrid, Spain \\ ${ }^{2}$ University Grenoble-Alpes, 38000 Grenoble, France \\ ${ }^{3}$ CEA-Grenoble, INAC/SP2M/NPSC, 38054 Grenoble, France \\ ${ }^{4}$ IMDEA Nanoscience, Autónoma University of Madrid, 28049 Madrid, Spain \\ *E-mail: arantzazu.nunez@ depeca.uah.es
}

In this work, we investigate the effects of deposition conditions on the structural and morphological properties of AlInN thin films deposited on p-doped Si (111) substrates by reactive radio-frequency sputtering. The aluminum composition can be tuned in the 0 to 0.36 range by changing the power applied to the aluminum target. $\mathrm{Al}$ incorporation leads to a change in the layer morphology and improvement of the rms surface roughness of the layers. The compact $\mathrm{Al}_{0.36} \mathrm{In}_{0.64} \mathrm{~N}$ sample grown at $550{ }^{\circ} \mathrm{C}$ exhibits intense room-temperature photoluminescence centered at $1.75 \mathrm{eV}$. 


\section{Introduction}

Owing to their unique properties ${ }^{1)}$, III-nitride semiconductors have become increasingly important in applications such as light-emitting diodes ${ }^{2)}$, laser diodes ${ }^{3)}$ or high-electron mobility transistors ${ }^{4)}$ and are intensively studied in other applications such as solar cells $^{5)}$ or energy harvesting ${ }^{6)}$. In the case of the ternary compound aluminum indium nitride $\left(\mathrm{Al}_{\mathrm{x}} \mathrm{In}_{1-\mathrm{x}} \mathrm{N}\right)$, its band gap can be tuned from near infrared $\left(\mathrm{InN}: 0.7 \mathrm{eV}^{7)}\right)$ to deep ultraviolet (AlN: $6.2 \mathrm{eV}^{8)}$ ), offering large possibilities to engineer the electronic structure for each specific application. For example, In-rich AlInN thin films have potential applications in multijunction solar cells since the band gap energy in the range from 0.7 to $2.4 \mathrm{eV}$ covers most part of the solar spectrum ${ }^{5)}$.

AlInN layers have been grown by different techniques, such as metal-organic chemical vapor deposition $(\mathrm{MOCVD})^{9)}$, molecular beam epitaxy $(\mathrm{MBE})^{10,11)}$, and sputtering deposition ${ }^{12-14)}$. Among them, the sputtering technique allows the deposition of AlInN at a low substrate temperature, because of the enhanced kinetic energy of the constituent ions given by the sputtering process of the targets itself. Although the films grown by MOCVD and MBE are single crystals, the sputtering process holds the advantage of preparing low-cost large-area polycrystalline AlInN films, which makes it feasible for scaling-up to the industry.

In this paper, we present a systematic study of the growth of In-rich $\mathrm{Al}_{\mathrm{x}} \operatorname{In}_{1-\mathrm{x}} \mathrm{N}$ layers deposited by reactive radio-frequency magnetron sputtering directly on p-doped silicon (111) substrates. The crystal structure, layer morphology and optical properties of these films are investigated as a function of both the RF power applied to the $\mathrm{Al}$ target and the substrate temperature. 


\section{Experimental methods}

$\mathrm{Al}_{\mathrm{x}} \mathrm{In}_{1-\mathrm{x}} \mathrm{N}$ samples were deposited on p-doped $\mathrm{Si}(111)$ substrates using a reactive RF-sputtering system (AJA International ATC ORION-3-HV) by co-sputtering 2 " confocal magnetron cathodes of pure In (4N5) and pure $\mathrm{Al}(5 \mathrm{~N})$ using pure nitrogen $(6 \mathrm{~N})$ as reactive gas. The substrate temperature was monitored using a thermocouple placed in direct contact with the substrate holder. Once the substrates were loaded to the sputtering chamber, they were outgassed for $30 \mathrm{~min}$ at $550{ }^{\circ} \mathrm{C}$ and then cooled down to the growth temperature. The targets and substrate were pre-sputtered with pure $\operatorname{Ar}(5 \mathrm{~N})$ plasma to remove surface contaminants. During the deposition of $\mathrm{Al}_{\mathrm{x}} \mathrm{In}_{1-\mathrm{x}} \mathrm{N}$, the distance between the targets and the substrate was fixed at $10.5 \mathrm{~cm}$, and the nitrogen flow rate and, sputtering pressure were kept at $14 \mathrm{sccm}$, and $0.47 \mathrm{~Pa}$, respectively, these parameters were previously optimized by our group ${ }^{15)}$. The RF power applied to the indium target was kept constant at $40 \mathrm{~W}$.

In the first set of samples (set A, samples S1-S6 in Table I) the RF power applied to the Al target $\left(\mathrm{P}_{\mathrm{Al}}\right)$ was varied from 0 to $150 \mathrm{~W}$ while keeping the substrate temperature at $\mathrm{T}_{\mathrm{s}}=300{ }^{\circ} \mathrm{C}$. The second set of samples (set B, samples S6-S9 in Table I) was grown at a constant $\mathrm{P}_{\mathrm{Al}}$ of $150 \mathrm{~W}$ and various $\mathrm{T}_{\mathrm{s}}$ values from 300 to $550{ }^{\circ} \mathrm{C}$.

The structural properties of the films were investigated by high-resolution X-ray diffraction (HRXRD) using an PANalytical X'Pert PRO MRD diffractometer. The surface morphology was evaluated by atomic force microscopy (AFM) in the tapping mode using a Veeco Dimension 3100 microscope. Data visualization and processing were carried out using WSxM software ${ }^{16)}$. The morphology and thickness of the layers were studied by field-emission scanning electron microscopy (FESEM) using a Zeiss Ultra 55 microscope. Photoluminescence (PL) measurements were carried out with 
excitation using a $23 \mathrm{~mW}$ controlled-power laser diode $(\lambda=488 \mathrm{~nm})$ focused onto a 50- $\mu \mathrm{m}$-diameter spot. The PL emission was collected into a 45-cm-focal-length Jobin-Yvon monochromator equipped with a charge-coupled-device (CCD) camera. The carrier concentration of the layers grown under the same conditions on sapphire substrates was analyzed by Hall Effect measurements in the conventional Van der Pauw geometry at room temperature (RT). X-ray photoelectron spectroscopy (XPS) measurements were performed under ultra-high vacuum conditions (UHV, at a base pressure of $\left.5 \times 10^{-10} \mathrm{mBar}\right)$ on layers grown on sapphire substrates using a monochromatic $\mathrm{Al} \mathrm{K \alpha}$ line as the exciting photon source $(\mathrm{h} v=1486.7 \mathrm{eV})$. A hemispherical energy analyzer (SPHERA-U7 analyzer pass energy) was set to $20 \mathrm{eV}$ for the XPS measurements to have a resolution of $0.6 \mathrm{eV}$. To compensate the built-up charge on the sample surface during the measurements, it was necessary to use a flood gun (Specs FG-500) with low-energy electrons of $3 \mathrm{eV}$ and $40 \mu \mathrm{A}$. The depth profile experiments were performed by alternating XPS measurements with cycles of Ar sputtering (Specs IQE-11A sputter gun).

\section{Results and discussion}

\subsection{Structural and morphological characterization}

The evolution of the crystalline structure of the AlInN films as a function of the RF power applied to the Al target $\left(\mathrm{P}_{\mathrm{Al}}\right)$ was evaluated by HRXRD. Figure 1 shows the $20 / \omega$ scans of the samples of set A. Only the peaks corresponding to the $\mathrm{Al}_{\mathrm{x}} \mathrm{In}_{1-\mathrm{x}} \mathrm{N}(0002)$ and Si (111) reflections coming from the layer and substrate, respectively, are detected within the analyzed $2 \theta$ range. This result confirms that the samples have wurtzite structure with the $c$-axis perpendicular to the surface. The $\mathrm{Al}_{\mathrm{x}} \operatorname{In}_{1-\mathrm{x}} \mathrm{N}(0002)$ reflection peak shifts towards larger diffraction angles when increasing $\mathrm{P}_{\mathrm{Al}}$, indicating a reduction 
in the lattice parameter $c$ from $5.714 \AA$ for $\mathrm{InN}(\mathrm{S} 1)$ to $5.446 \AA$ for $\mathrm{AlInN}$ deposited with $\mathrm{P}_{\mathrm{Al}}=150 \mathrm{~W}$ (S6). The $\mathrm{Al}$ mole fraction $(x)$ of the samples, estimated using Vegard's law ${ }^{17)}$ and assuming fully relaxed layers, evolves from $x=0$ to 0.36 for this range of $\mathrm{P}_{\mathrm{Al}}$ (see Table I, samples $\mathrm{S} 1$ to $\mathrm{S} 6$ ).

Figure 2(a) shows the dependence of the root-mean square (rms) surface roughness of the AlInN films with the Al RF power. The rms surface roughness is extracted from $2 \times 2 \mu \mathrm{m}^{2}$ scanning area AFM micrographs. The InN layer $\left(\mathrm{S} 1\right.$, with $\left.\mathrm{P}_{\mathrm{Al}}=0\right)$ exhibits an rms surface roughness of $11.6 \mathrm{~nm}$ and a close-packed morphology, as shown in the cross-sectional FESEM and AFM images in Figs. 2(b) and 2(c), respectively. For $\mathrm{P}_{\mathrm{Al}}=75 \mathrm{~W}(\mathrm{~S} 2)$ the $\mathrm{Al}$ incorporates $(x=0.13)$ to the layer reducing the rms roughness to $6.7 \mathrm{~nm}$ without changing the layer morphology (not shown). However, when increasing $\mathrm{P}_{\mathrm{Al}}$ from 75 to $150 \mathrm{~W}$ (and thus the $\mathrm{Al}$ concentration from $x=0.13$ to 0.36 ) the morphology of the layer changed from close-packed to compact and the rms surface roughness decreases by almost a factor of 2. Cross-sectional FESEM and AFM images of the $\mathrm{Al}_{0.36} \mathrm{In}_{0.64} \mathrm{~N}$ sample are shown in Figs. 2(d) and 2(e), respectively. The sample surface does not show metal droplets even when increasing Al layer content, pointing to deposition on a N-rich environment. The change in layer morphology is associated with an increase in the growth rate by almost a factor of 2 (from $107 \mathrm{~nm} / \mathrm{h}$ to $210 \mathrm{~nm} / \mathrm{h}$ ) between both AlInN layers (S2 and S6). The obtained changes in rms surface roughness and growth rate cannot be explained only by the higher concentration of Al without considering the increased kinetic energy available for the deposition process when increasing $\mathrm{P}_{\mathrm{Al}}$.

In the second set of samples (set $\mathrm{B}$, samples S6-S9), $\mathrm{P}_{\mathrm{Al}}$ was kept constant at $150 \mathrm{~W}$, while the substrate temperature was varied from $\mathrm{T}_{\mathrm{s}}=300$ to $550{ }^{\circ} \mathrm{C}$. From the $2 \theta / \omega$ 
X-ray scan shown in Fig. 3, the $\mathrm{Al}_{\mathrm{x}} \mathrm{In}_{1-\mathrm{x}} \mathrm{N}$ (0002) diffraction angle barely changes, implying that there is almost no change in the alloy composition $(x \approx 0.36)$. Table $\mathrm{I}$ shows a summary of the evolution of the rms surface roughness of the $\mathrm{Al}_{0.36} \mathrm{In}_{0.64} \mathrm{~N}$ layers vs substrate temperature at $\mathrm{P}_{\mathrm{Al}}=150 \mathrm{~W}$. The obtained rms surface roughness can be considered constant being $3.7 \pm 0.9 \mathrm{~nm}$. FESEM and AFM images indicate that the layer morphology maintains within the $T_{s}$ range under study (see Figs. 4(a) and 4(b), respectively, as an example of sample S9). However, the growth rate decreases from $210 \mathrm{~nm} / \mathrm{h}$ to $116 \mathrm{~nm} / \mathrm{h}$, owing to an increase in adatom mobility which leads to a higher desorption of physi-adsorbed atoms.

\subsection{Optical properties}

The evolution of PL intensity with temperature $(T=5 \mathrm{~K}-300 \mathrm{~K})$ of the $\mathrm{Al}_{0.36} \operatorname{In}_{0.64} \mathrm{~N}$ layer grown at $550{ }^{\circ} \mathrm{C}(\mathrm{S} 9)$ was investigated. Figure 5(a) shows that the PL emission peak redshifts $30 \mathrm{meV}$ when increasing the measurement temperature. Moreover, the strong PL emission at room-temperature is indicative of high-quality AlInN obtained by RF-magnetron sputtering under the optimized conditions.

The integrated PL intensity as a function of temperature is plotted in Fig. 5(b). At room-temperature, the PL emission drops to $60 \%$ of that at a low temperature ( $\mathrm{T}=5 \mathrm{~K})$. This thermal stability is tentatively attributed to carrier localization in high In-content fluctuations or impurities. The thermal quenching of PL intensity, $I(T)$, can be described considering one nonradiative recombination channel ${ }^{18)}$ :

$$
\mathrm{I}(\mathrm{T})=\frac{\mathrm{I}(\mathrm{T}=0 \mathrm{~K})}{1+a \cdot \exp \left(-\frac{\mathrm{E}_{a}}{\mathrm{k}_{\mathrm{B}} \mathrm{T}}\right)}
$$

where $E_{a}$ is the average energetic barrier required for carriers to escape from their localization and reach the nonradiative recombination centers, $k_{B} T$ is the thermal 
energy, and $a$ is a fitting constant associated with a nonradiative-to-radiative recombination ratio. The agreement of experimental data to Eq. (1) is illustrated by the solid line in Fig. 5(b) obtaining an activation energy $E_{a}=24.2 \pm 1.4 \mathrm{meV}$ with an $a$ value of 1.4 .

A carrier concentration of $2.7 \times 10^{20} \mathrm{~cm}^{-3}$ has been estimated from Hall measurements for a similar AlInN sample deposited on sapphire under the same conditions. The values of resistivity $\left(\rho_{s}=3.7 \mathrm{~m} \Omega \cdot \mathrm{cm}\right)$ and mobility $\left(\mu \cong 6.2 \mathrm{~cm}^{2} \mathrm{~V}^{-1} \mathrm{~s}^{-1}\right)$ are also in close agreement with those obtained by Liu et al. $\left(\rho_{s}=1.2 \mathrm{~m} \Omega \cdot \mathrm{cm}\right.$ and $\left.\mu=11.4 \mathrm{~cm}^{2} \mathrm{~V}^{-1} \mathrm{~s}^{-1}\right)$ for $\mathrm{Al}_{0.28} \mathrm{In}_{0.72} \mathrm{~N}$ layers ${ }^{14)}$. The obtained $\mathrm{PL}$ emission energy is $1.75 \mathrm{eV}$, approximately $\sim 0.5 \mathrm{eV}$ higher than that expected in samples with low carrier concentration $^{19)}$, which is attributed to the Burstein-Moss effect ${ }^{20)}$ induced by the high residual carrier concentration of the layers.

Several sources of this high carrier concentration in high-In content AlInN alloys have been proposed, such as, nitrogen vacancies $\left(\mathrm{V}_{\mathrm{N}}\right)$, and hydrogen and oxygen impurities $^{21-23)}$. XPS measurements of sample S9 (grown on sapphire) were performed to elucidate the existence of $\mathrm{O}$ impurities within the sample. The experiments were performed under UHV conditions of $5 \times 10^{-10} \mathrm{mBar}$ to reduce the effect of layer contamination during etching. From these experiments, a homogeneously distributed $\mathrm{O}$ concentration of $\sim 4 \%$ was detected within the sample depth. This result is in agreement with the reported one by Bhuiyan et $a .^{23)}$ and Yoshimoto et al. ${ }^{24)}$, who observed a relationship between $\mathrm{O}$ concentration and the induced blue-shift of the emission of $\mathrm{InN}$ samples with similar oxygen contents. Thus, this impurity contamination could be an important factor for the high carrier concentration in the samples. 


\section{Conclusions}

We have presented the successful growth of high-In content $\mathrm{Al}_{\mathrm{x}} \mathrm{In}_{1-\mathrm{x}} \mathrm{N}$ layers on p-doped Si (111) substrates by reactive RF-sputtering. The effects of the power applied to the aluminum target and the substrate temperature on the structural, morphological, and optical properties of $\mathrm{Al}_{\mathrm{x}} \mathrm{In}_{1-\mathrm{x}} \mathrm{N}$ layers have been studied. The aluminum composition can be tuned from 0 to $36 \%$ by changing the power applied to the aluminum target from 0 to $150 \mathrm{~W}$. The change in substrate temperature from 300 to $550{ }^{\circ} \mathrm{C}$ leads to a decrease in growth rate while the $\mathrm{Al}$ content is kept almost constant. In particular, the sample grown at $550{ }^{\circ} \mathrm{C}$ and $150 \mathrm{~W}$ power applied to the aluminum target (Al mole fraction $~ 0.36$ ) shows a compact morphology with an rms surface roughness of $3 \mathrm{~nm}$ and a high RT PL emission intensity centered at $1.75 \mathrm{eV}$.

\section{Acknowledgements}

Partial financial support was provided by the Spanish Government projects TEC2012 37958 C02 01 and TEC2015-71127-C2-2-R, the Community of Madrid project S2013/MIT 2790, the project CCG2014/EXP 051, and an FPI Grant from the Alcalá University, and by a Marie Curie IEF Grant 331745. 


\section{References}

1) S. C. Jain, M. Willander, J. Narayan, and R. Van Overstraeten, J. Appl. Phys. 87, 965 (2000).

2) C. Weisbuch, M. Piccardo, L. Martinelli, J. Iveland, J. Peretti, and J. S. Speck, Phys. Status Solidi (A), 212, 899 (2015).

3) G. Muziol, M. Siekacz, H. Turski, P. Wolny, S. Grzanka, E. Grzanka, A. Feduniewicz-Żmuda, J. Borysiuk, K. Sobczak, J. Domagała, A. NowakowskaSiwińska, I. Makarowa, P. Perlin, and C. Skierbiszewski, J. Cryst. Growth 425, 398 (2015).

4) N. Espinosa, S. U. Schwarz, V. Cimalla, and O. Ambacher, Sens. Actuators B 210, 633 (2015).

5) A. Yamamoto, M. R. Islam, T. T. Kang, and A. Hashimoto, Phys. Status Solidi (C) 7, 1309 (2010).

6) N. Gogneau, P. Chrétien, E. Galopin, S. Guilet, and L. Travers, Appl. Phys. Lett. 104, 213105 (2014).

7) J. Wu, W. Walukiewicz, K. M. Yu, J. W. Ager, E. E. Haller, H. Lu, W. J. Schaff, Y. Saito, and Y. Nanishi, Appl. Phys. Lett. 80, 3967 (2002).

8) W. M. Yim, E. J. Stofko, P. J. Zanzucchi, J. I. Pankove, M. Ettenberg, and S. L. Gilbert, J. Appl. Phys. 44, 292 (1973).

9) C. Hums, J. Bläsing, A. Dadgar, A. Diez, T. Hempel, J. Christen, A. Krost, K. Lorenz, and E. Alves, Appl. Phys. Lett. 90, 022105 (2007).

10) W. C. Chen, Y.H. Wu, J.S. Tian, T.C. Yen, P.Y. Lin, J.Y. Chen, C.N. Hsiao, and L. Chang, ISRN Nanomater., (2014).

11) W.C. Chen, Y.H. Wu, C.Y. Peng, C.N. Hsiao, and L. Chang, Nanoscale Research Lett. 9 [1], 1 (2014).

12) C. J. Dong, M. Xu, Q. Y. Chen, F. S. Liu, H. P. Zhou, Y. Wei, and H. X. Ji, J. Alloys Compd. 479, 812 (2009).

13) Q. Han, C. Duan, G. Du, W. Shi, and L. Ji, J. Electron. Mater. 39, 489 (2010).

14) H. F. Liu, C. C. Tan, G. K. Dalapati, and D. Z. Chi, J. Appl. Phys. 112, 63114 (2012).

15) S. Valdueza-Felip, F.B. Naranjo, M. González-Herráez, L. Lahourcade, E. Monroy, and S. Fernández, J. Cryst. Growth 312, 2689 (2010).

16) I. Horcas, R. Fernández, J. M. Gómez-Rodríguez, J. Colchero, J. Gómez-Herrero, A. M. Baro, Rev. Sci. Instrum. 78, 013705 (2007). 
17) L. Vegard, Zeitschrift für Physik 5, 17 (1921).

18) M. Leroux, N. Grandjean, B. Beaumont, G. Nataf, F. Semond, J. Massies, and P. Gibart, J. Appl. Phys. 86, 3721 (1999).

19) J. Kamimura, T. Kouno, S. Ishizawa, A. Kikuchi, and K. Kishino. J. Cryst. Growth 300 160, (2007).

20) H. He, Y. Cao, R. Fu, W. Guo, Z. Huang, M. Wang, C. Huang, and H. Wang, Appl. Surf. Sci. 256, 1812 (2010).

21) J. Wu, J, Appl. Phys. 106, 011101 (2009).

22) V. Darakchieva, K. Lorenz, N. P. Barradas, E. Alves, B. Monemar, M. Schubert, N. Franco, C. L. Hsiao, L. C. Chen, W. J. Schaff, L. W. Tu, T. Yamaguchi, and Y. Nanishi, Appl. Phys. Lett. 96, 081907 (2010).

23) A. G. Bhuiyan, K. Sugita, K. Kasashima, A. Hashimoto, A. Yamamoto, and V. Y. Davydov, Appl. Phys. Lett. 83, 4788 (2003).

24) M. Yoshimoto, H. Yamamoto, W. Huang, H. Harima, J. Saraie, A. Chayahara, and Y. Horino, Appl. Phys. Lett. 83, 3480 (2003). 


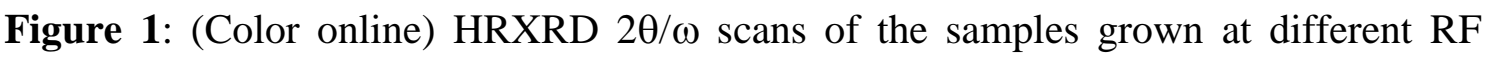
powers applied to the $\mathrm{Al}$ target (set A).

Figure 2: (a) Evolution of the rms surface roughness of $\mathrm{Al}_{\mathrm{x}} \mathrm{In}_{1-\mathrm{x}} \mathrm{N}$ samples as a function of $\mathrm{P}_{\mathrm{Al}}$, with $\mathrm{T}_{\mathrm{s}}=300^{\circ} \mathrm{C}$. AFM $\left(2 \times 2 \mu \mathrm{m}^{2}\right)$ and FESEM images of two samples grown at $300{ }^{\circ} \mathrm{C}$ and various $\mathrm{P}_{\mathrm{Al}}$ values: (b) FESEM and (c) AFM images of an InN layer (S1); (d) FESEM and (e) AFM images of $\mathrm{Al}_{0.36} \mathrm{In}_{0.64} \mathrm{~N}(\mathrm{~S} 6)$.

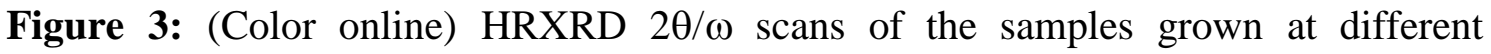
substrate temperatures (set B).

Figure 4: (a) FESEM and (b) $\operatorname{AFM}\left(2 \times 2 \mu \mathrm{m}^{2}\right)$ images of an $\mathrm{Al}_{0.36} \operatorname{In}_{0.64} \mathrm{~N}$ layer grown at $550{ }^{\circ} \mathrm{C}(\mathrm{S} 9)$.

Figure 5: (Color online) (a) Variation of the PL emission energy with temperature and (b) thermal evolution of the integrated PL intensity of the $\mathrm{Al}_{0.36} \mathrm{In}_{0.64} \mathrm{~N}$ layer grown at $550{ }^{\circ} \mathrm{C}$ (S9). The solid line is the fit to Eq. (1). 
Table I. Summary of the growth conditions and structural properties of the $\mathrm{Al}_{\mathrm{x}} \mathrm{In}_{1-\mathrm{x}} \mathrm{N}$ samples from sets A (S1-S6) and B (S6-S9).

\begin{tabular}{|c|c|c|c|c|c|c|}
\hline \multirow[t]{2}{*}{ Sample } & \multirow[t]{2}{*}{$\begin{array}{l}P_{A l} \\
(W)\end{array}$} & \multirow[t]{2}{*}{$\begin{array}{l}T_{s} \\
\left({ }^{\circ} \mathrm{C}\right)\end{array}$} & \multicolumn{2}{|c|}{$\begin{array}{c}\text { Composition } \\
\text { (HRXRD) }\end{array}$} & \multirow{2}{*}{$\begin{array}{c}\text { RMS } \\
\text { (AFM) } \\
(\mathrm{nm})\end{array}$} & \multirow{2}{*}{$\begin{array}{c}\text { Thickness } \\
\text { (SEM) } \\
\text { (nm) }\end{array}$} \\
\hline & & & Al & In & & \\
\hline S1 & 0 & 300 & & & 11.3 & 530 \\
\hline S2 & 75 & 300 & 0.13 & 0.87 & 6.7 & 430 \\
\hline S3 & 85 & 300 & 0.19 & 0.81 & 5.6 & \\
\hline S4 & 105 & 300 & 0.24 & 0.76 & 6.3 & \\
\hline S5 & 125 & 300 & 0.29 & 0.71 & 5.3 & \\
\hline S6 & 150 & 300 & 0.36 & 0.64 & 3.1 & 840 \\
\hline S7 & 150 & 350 & 0.37 & 0.63 & 3.4 & \\
\hline 58 & 150 & 450 & 0.37 & 0.63 & 4.8 & \\
\hline S9 & 150 & 550 & 0.36 & 0.64 & 3.5 & 460 \\
\hline
\end{tabular}


Figure 1

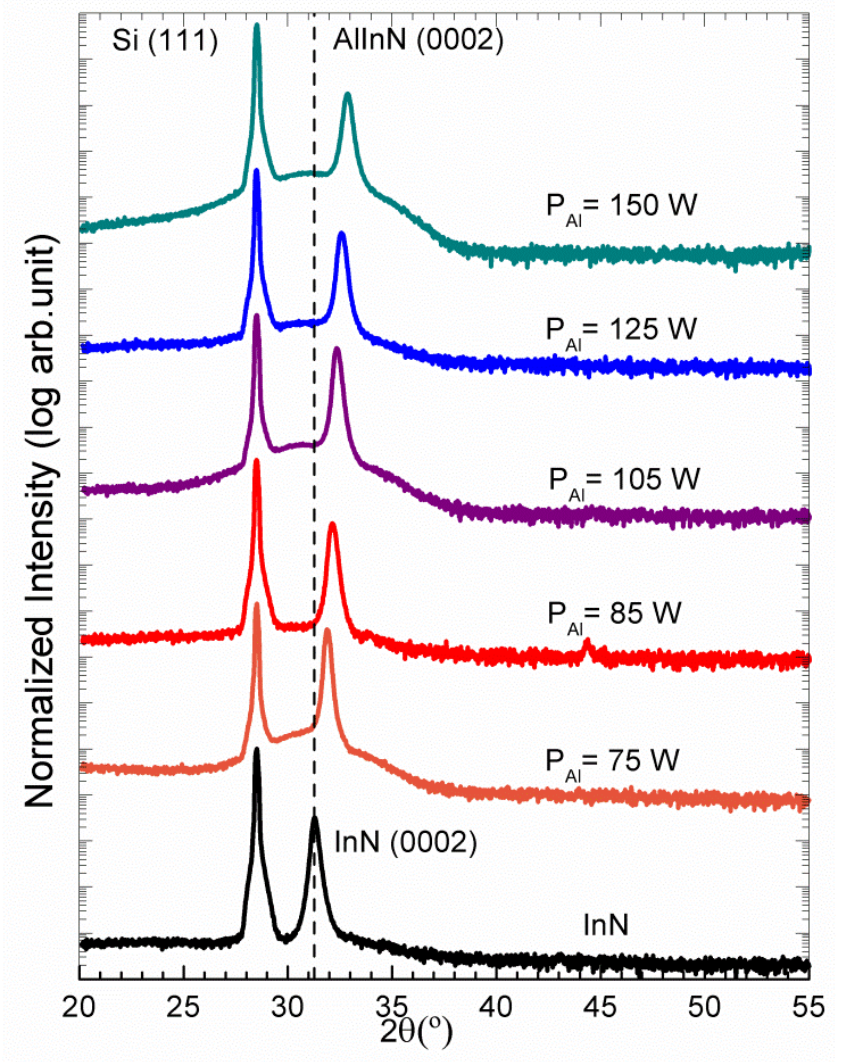

Figure 2
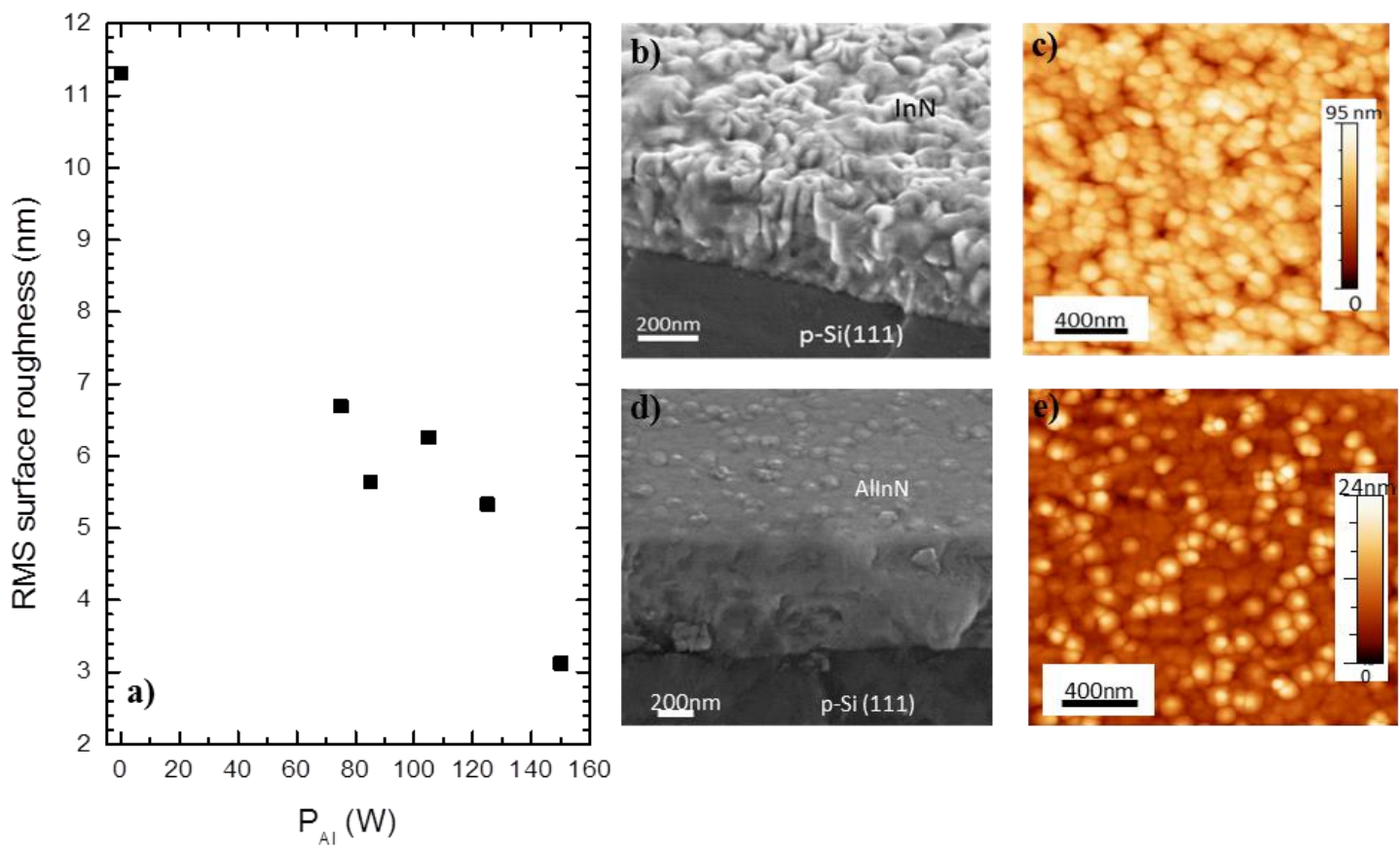
Figure 3

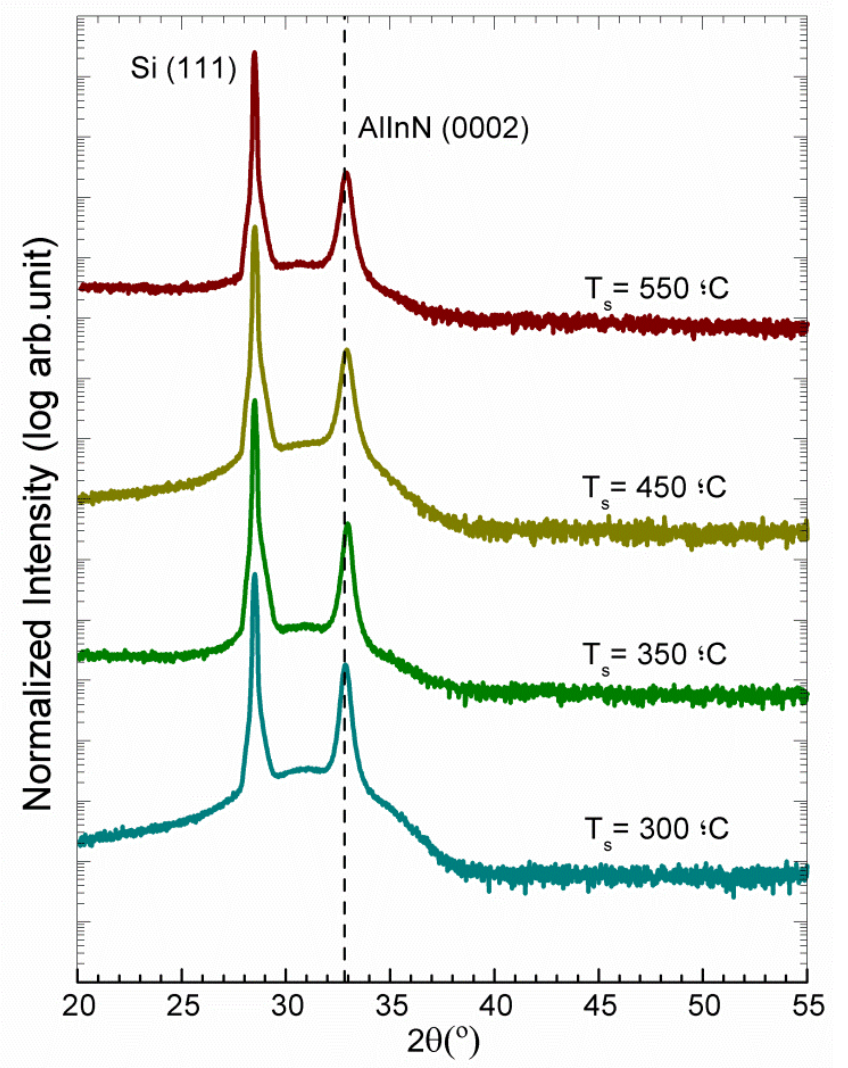

Figure 4
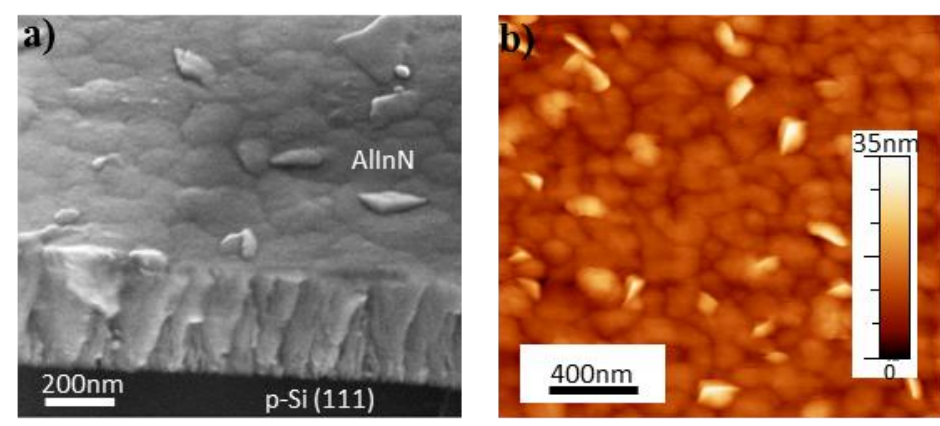
Figure 5
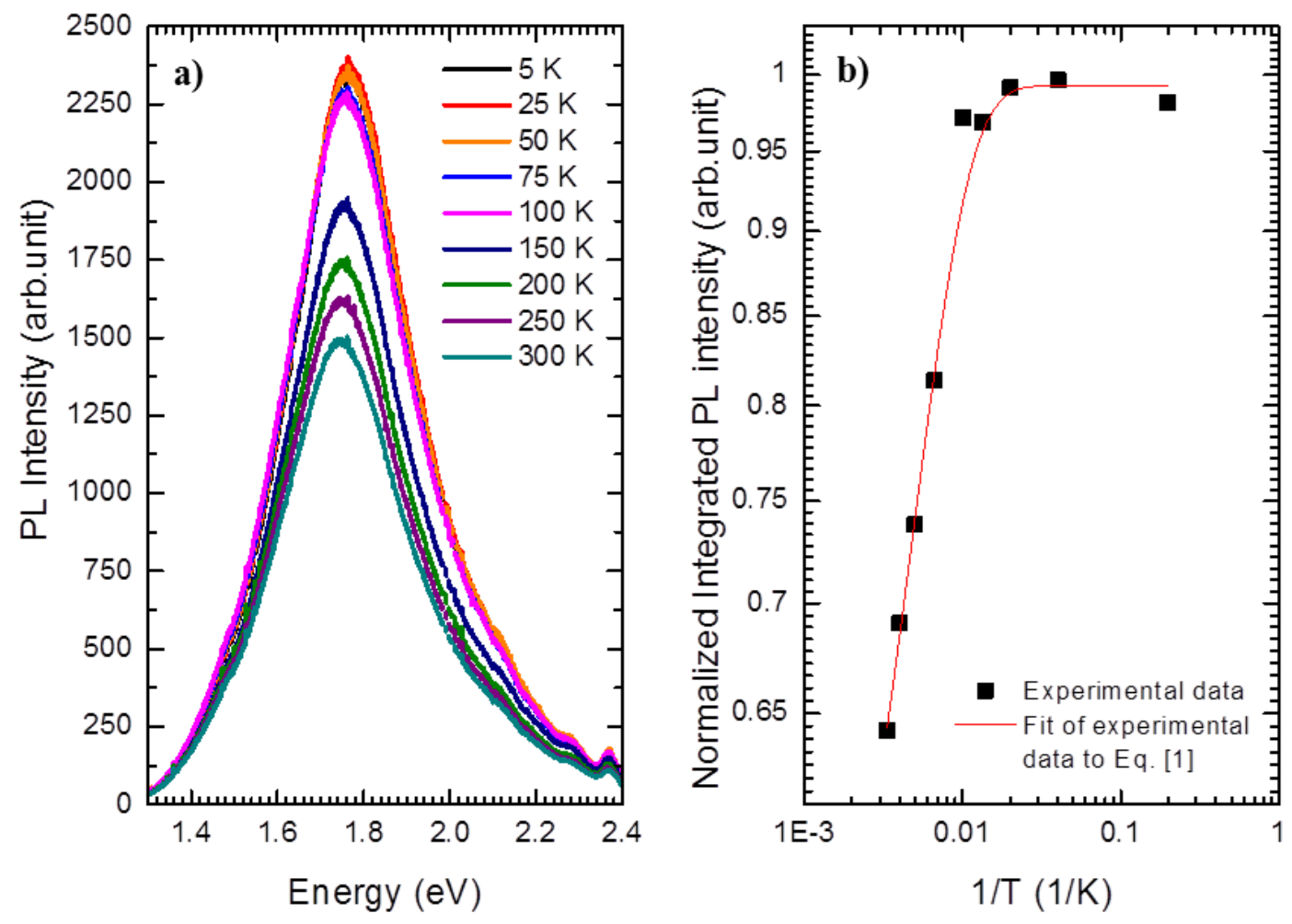